\title{
Fine-scale ecological and anthropogenic variables predict the habitat use and detectability of sloth bears in the Churia habitat of east Nepal
}

\author{
Manoj Pokharel ${ }^{1}$, Asmit Subba ${ }^{2}$, Dipa Rai ${ }^{3}$, Simrik Bhandari ${ }^{4}$, and Yadav Ghimire ${ }^{5}$ \\ ${ }^{1}$ Tri-Chandra Multiple Campus \\ ${ }^{2}$ Tribhuvan University \\ ${ }^{3}$ GoldenGate International College \\ ${ }^{4}$ Kathmandu University \\ ${ }^{5}$ Friends of Nature
}

October 6, 2021

\begin{abstract}
Once widespread throughout the tropical forests of the Indian Subcontinent, the sloth bears have suffered a rapid range collapse and local extirpations in the recent decades. A significant portion of their current distribution range is situated outside of the protected areas (PAs). These unprotected sloth bear populations are under tremendous human pressures, but little is known about the patterns and determinants of their occurrence in most of these regions. The situation is more prevalent in Nepal where virtually no systematic information is available for sloth bears living outside of the PAs. We undertook a sign survey-based single-season occupancy study intending to overcome this information gap for the sloth bear populations residing in the Trijuga forest of southeast Nepal. Sloth bear sign detection/non-detection data and field-based covariates data were collected at the 74 randomly chosen $4-\mathrm{km} 2$ grid cells using a varying number of $400 \mathrm{~m}$ long transects in each grid cell. From our results, the model-averaged estimate of site use probability ( $\psi \pm \mathrm{SE}$ ) was estimated to be $0.432 \pm 0.039$, which is a $13 \%$ increase from the naïve estimate (0.297) not accounting for imperfect detections of sloth bear signs. The presence of termite mounds and the distance to the nearest water source were the most important variables affecting the habitat use probability of sloth bears. The average site-level detectability $(\mathrm{p} \pm \mathrm{SE}$ ) of sloth bear signs was estimated to be $0.195 \pm 0.003$ and was significantly determined by the index of human disturbances. We recommend considering the importance of fine-scale ecological and anthropogenic factors in predicting the sloth bear-habitat relationships across their range in the Churia habitat of Nepal.
\end{abstract}

\section{Hosted file}

Main_document_Pokharel et al..docx available at https://authorea.com/users/293302/articles/ 540575-fine-scale-ecological-and-anthropogenic-variables-predict-the-habitat-use-anddetectability-of-sloth-bears-in-the-churia-habitat-of-east-nepal 

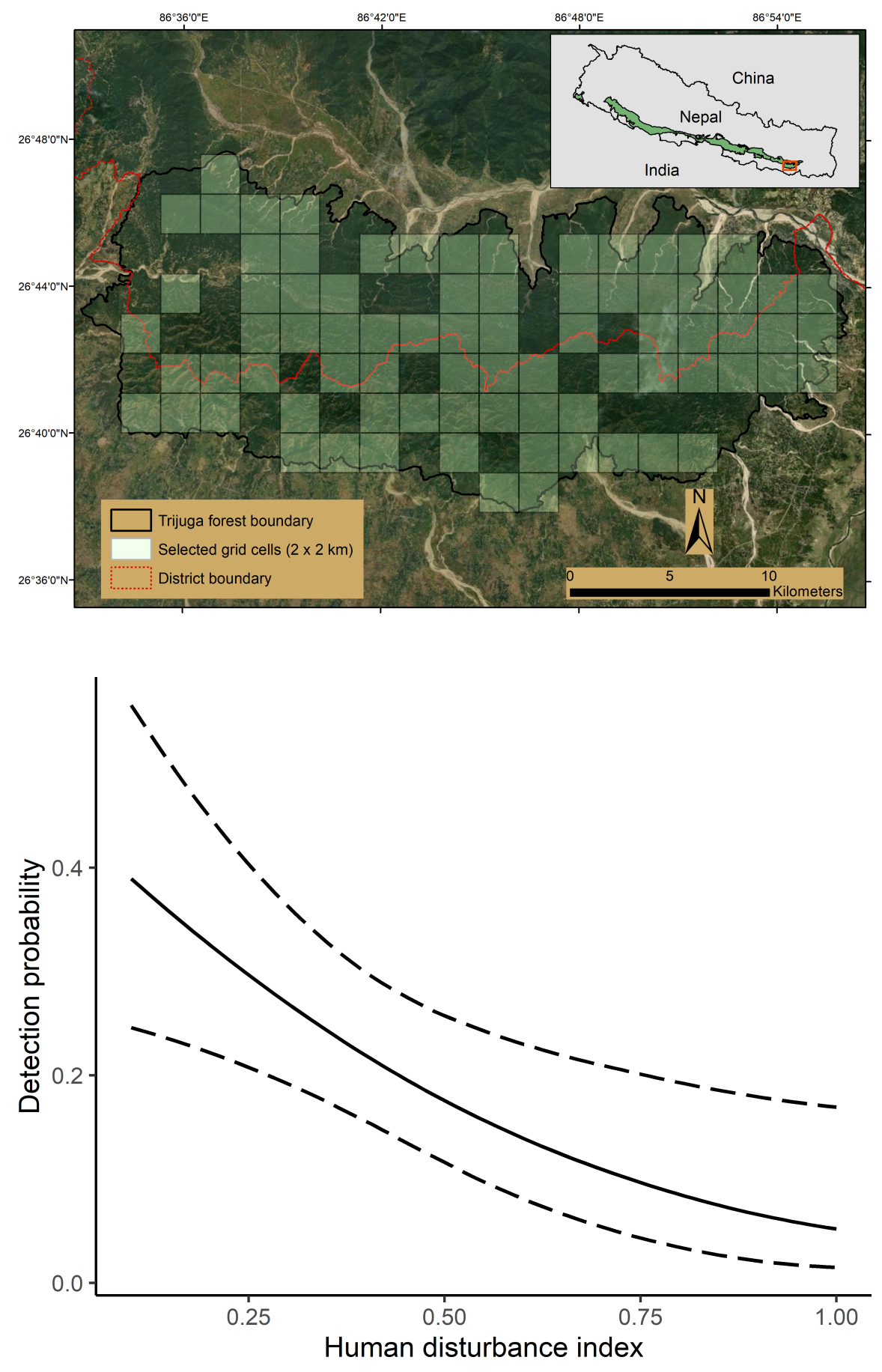

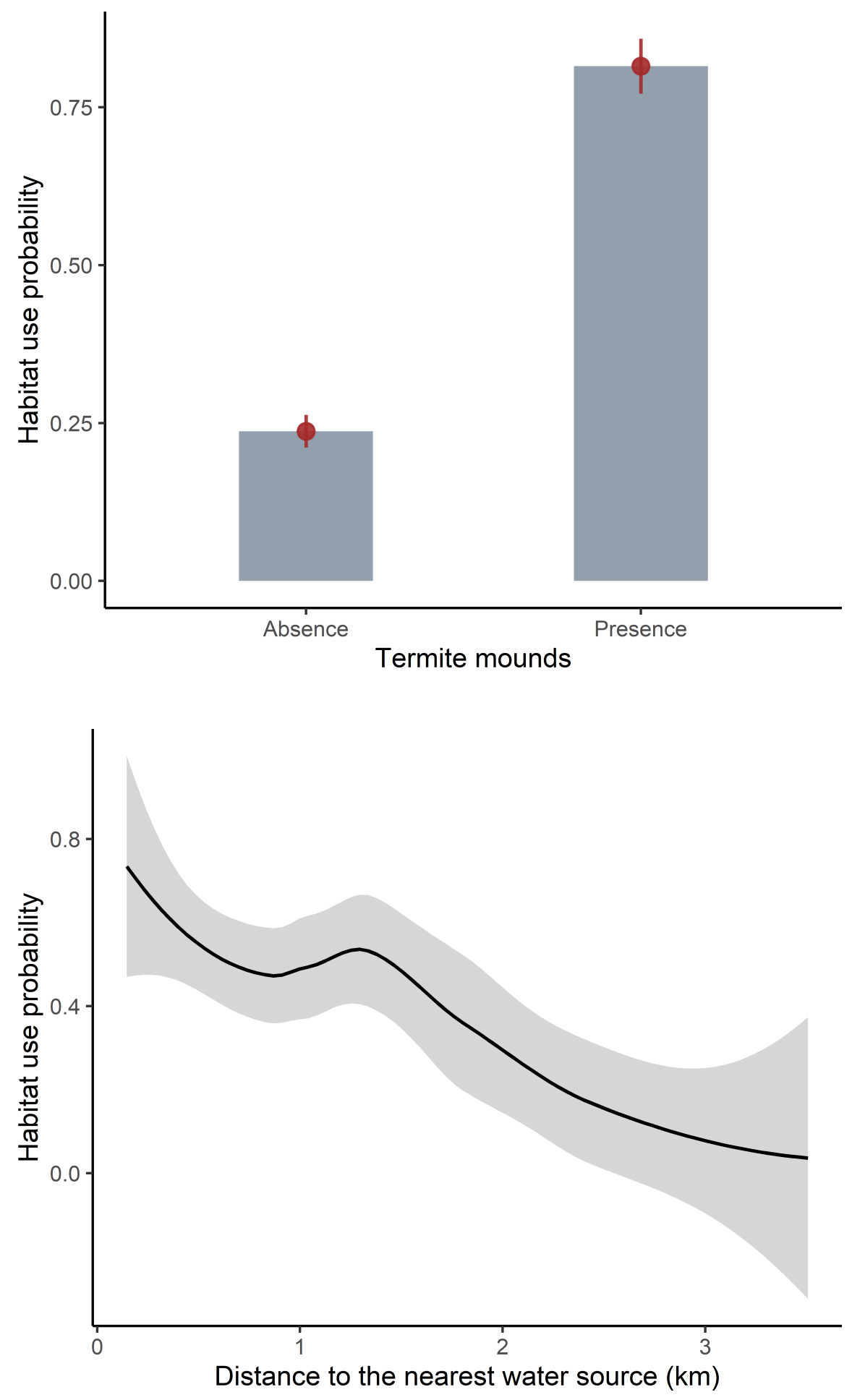


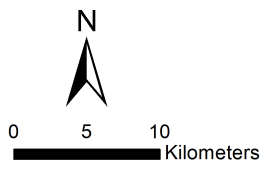

(a)

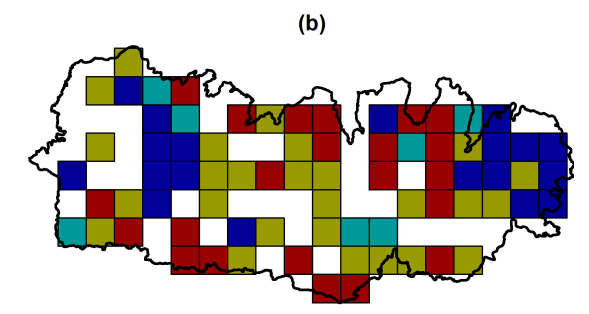

Sloth bear signs

Estimated site use probability

$\square$ Detected
$\square$ Not detected

$0.002600-0.180800$

$0.180801-0.466100$

$\square 0.466101-0.711100$

$0.711101-0.979600$ 